\title{
Apoptosis-independent Poor Morphology of Bovine Embryos Produced by Multiple Ovulation
}

\author{
S Ikeda ${ }^{1,2}$, JM Prendes ${ }^{3}$, C Alonso-Montes ${ }^{2}$, A Rodríguez ${ }^{2}$, C Díez $^{2}$, M Kitagawa ${ }^{1}$, Imai ${ }^{1}$ and E Gómez $^{2}$ \\ ${ }^{1}$ Livestock Farm of Graduate School of Agriculture, Kyoto University, Kyo-Tamba, Kyoto Prefecture, Japan; ${ }^{2}$ Area de Genética y Reproducción \\ Animal, Servicio Regional de Investigación y Desarrollo Agroalimentario (SERIDA), Gijón, Asturias, Spain; ${ }^{3}$ Cooperativa de Agricultores de Gijón, \\ Gijón, Asturias, Spain
}

\begin{abstract}
Contents
In multiple ovulation and embryo transfer (MOET) programmes in cattle, a considerable number of morphologically poor-quality embryos continue to be produced; this is one of the limiting factors of the technique. Apoptosis has often been implicated in developmental arrest and fragmentation; these are regarded as poor traits of embryonic quality in mammalian pre-implantation embryos. In the present study, apoptosis was assessed in morphologically poor-quality embryos in comparison with good-quality embryos that were recovered from a MOET programme. Retarded embryos (two to 16 cell stage), morulae with severe fragmentation and morphologically goodquality morulae recovered from superstimulated cows at day 7 post-insemination were subjected to TdT-mediated dUTP nick-end labelling (TUNEL) and Hoechst staining. Cell nuclei that showed both TUNEL staining and apoptotic morphology were considered to be apoptotic. Apoptotic index (AI) was calculated as the percentage of apoptotic cells per embryo. Fifteen of 17 retarded embryos and 10 of 15 morphologically poor-quality morulae did not show signs of apoptosis. The mean AIs in the morphologically poor-quality embryos (two to 16 cell stage, $2.2 \%$; poor morulae, $1.3 \%$ ) were as low as that in the good-quality embryos $(2.9 \%)$. These results suggest that another mode of developmental arrest and/or fragmentation that is independent of apoptosis occurs in morphologically poor-quality embryos recovered from MOET programmes.
\end{abstract}

\section{Introduction}

In multiple ovulation and embryo transfer (MOET) programmes in cattle, the high proportion of poorquality embryos continues to be a major factor that limits the efficiency of the technique (Armstrong 1993). However, the mechanisms underlying the defective morphology are largely unknown. Quality assessment of pre-implantation embryos is mainly based on the developmental stage and morphological criteria, and poor-quality embryos are commonly characterized by developmental retardation or the occurrence of extruded blastomeres (Lindner and Wright 1983; Robertson and Nelson 1998) which is often called fragmentation (Alikani et al. 1999; Mateusen et al. 2005). In vitro produced mammalian pre-implantation embryos also often show unfavourable morphology in terms of embryo quality, accompanied by cellular fragmentation. An increasing body of evidences implicates apoptosis in mammalian embryonic arrest and/or fragmentation (Jurisicova et al. 1996; Jurisicova and Acton 2004; Mateusen et al. 2005), including bovine embryos (Yang and Rajamahendran 2002). The presence of apoptosis in poor-quality embryos may imply the existence of self-elimination mechanisms to avoid the inheritance of defects (Jurisi- cova et al. 1998; Hardy et al. 2003). In this study, apoptosis in morphologically poor-quality embryos obtained in a MOET programme was examined. Unexpectedly, the levels of apoptosis in these embryos were as low as those in morphologically good-quality embryos.

\section{Materials and Methods}

All chemicals, except where specified otherwise, were purchased from Sigma-Aldrich (St Louis, MO, USA).

\section{Multiple ovulation}

Asturiana de los Valles and Asturiana de la Montaña cows $(n=9)$ were superstimulated with porcine gonadotropin (Pluset ${ }^{\circledR}$; Calier, Barcelona, Spain) that was administered twice daily (08:00 hours and 20:00 hours) for 4 days (first day, $2.5 \mathrm{ml}$; second day, $2.0 \mathrm{ml}$; third day, $1.5 \mathrm{ml}$; fourth day, $1.0 \mathrm{ml}: 14 \mathrm{ml}$ in total, equivalent to $700 \mathrm{IU}$ FSH and $700 \mathrm{IU}$ LH). On the last day of stimulation, the cows received prostaglandin F2 $\alpha$ (Enzaprost $^{\circledR}$; CEVA Sante Animale, Libourne, France) three times; $40 \mathrm{mg}$ at 08:00 hours, $20 \mathrm{mg}$ at 12:00 hours and $40 \mathrm{mg}$ at 20:00 hours. GnRH (100 $\mu \mathrm{g}$, Cystoreline ${ }^{\circledR}$; CEVA Sante Animale) was administered $36 \mathrm{~h}$ after the last FSH administration, and all animals were inseminated at 0,12 and $24 \mathrm{~h}$ after the GnRH administration.

\section{Embryo recovery}

On day 7 after the first insemination, each uterine horn was flushed with $500 \mathrm{ml}$ of COMPLETE Ultra Embryo Flushing Solution (ICPbio, Auckland, New Zealand) by using a two-way catheter. The flushed solution was concentrated by using an EM-con ${ }^{\circledR}$ filter (Immuno Systems, Spring Valley, WI, USA). The embryos were recovered from the concentrates, transferred into Emcare ${ }^{\circledR}$ Embryo Holding Solution (ICPbio) and evaluated following IETS criteria (Robertson and Nelson 1998) under a stereoscopic microscope. Morulae that were coded 1 (excellent) or 2 (fair) were considered as good quality and those coded 3 (poor) and retarded embryos (two to 16 cell stage) as poor quality. Unfertilized ova were discarded.

\section{TUNEL}

For the assessment of apoptosis in the embryos, we used terminal deoxynucleotidyl transferase-mediated dUTP 
nick-end labelling (TUNEL) that detects in situ DNA fragmentation; this is one of the biochemical hallmarks of apoptosis, in combination with nuclear morphological criteria (Gjorret et al. 2003) that can be seen by Hoechst staining. The embryos were fixed in $4 \%(\mathrm{w} / \mathrm{v})$ PBS-buffered paraformaldehyde and permeabilized with PBS containing $0.5 \%(\mathrm{v} / \mathrm{v})$ Triton-X 100. After washing with PBS containing $0.01 \%(\mathrm{w} / \mathrm{v})$ PVA (PBS-PVA), the samples were incubated for $1 \mathrm{~h}$ at $37^{\circ} \mathrm{C}$ in a TUNEL reaction mixture (In Situ Cell Death Detection Kit; Roche, Penzberg, Germany). The negative control did not contain TdT, while the positive control was subjected to TUNEL after treatment with $100 \mathrm{U} / \mathrm{ml}$ DNase I for $1 \mathrm{~h}$ at $37^{\circ} \mathrm{C}$. After the TUNEL reaction, all the nuclei were stained with $0.001 \%$ (w/v) Hoechst 33342 diluted in PBS-PVA for $10 \mathrm{~min}$. The embryos were mounted onto a slide glass with droplets of glycerol containing $2.5 \%(\mathrm{w} / \mathrm{v})$ 1,4-diazabicyclo[2.2.2] octane and flattened with a coverslip. The samples were examined under an Olympus IX50 fluorescence microscope (Olympus, Tokyo, Japan). The WB and WU filters were used for the detection of TUNEL and Hoechst staining respectively. An embryonic cell was regarded as apoptotic when the cell displayed both positive TUNEL staining and apoptotic morphology, i.e. nuclear condensation with or without fragmentation (Gjorret et al. 2003). The apoptotic index (AI) was calculated as the percentage of apoptotic cells per embryo.

\section{Statistical analysis}

Ratios of the embryos showing apoptosis were compared by the chi-square test followed by Tukey's multiple comparison (Ryan 1960). The AIs were compared by analysis of variance followed by post hoc Sheffe's test. Statistical significance was assumed at $\mathrm{p}<0.05$.

\section{Results}

The results are shown in Table 1 and Fig. 1. More than half of the morphologically good-quality morulae had at least one nucleus displaying morphological and biochemical (TUNEL) apoptotic traits, but their average AI was low $(2.9 \%)$. Fifteen of 17 retarded embryos and 10 of 15 morphologically poor-quality morulae did not show apoptosis (Fig. 1A-A" and B-B" ). Only two of 17 retarded embryos showed apoptosis at 12.5 (one of eight cells) and $25 \%$ (two of eight cells) respectively. The

Table 1. Assessment of apoptosis in two to 16 cell stage embryos and morulae with poor or good morphological quality recovered from superstimulated cows at day 7 post-insemination

\begin{tabular}{lccc}
\hline Embryo & $\begin{array}{c}\text { Number of } \\
\text { embryos }\end{array}$ & $\begin{array}{c}\text { Number (\%) of } \\
\text { embryos with } \\
\text { apoptosis }\end{array}$ & $\begin{array}{c}\text { Apoptotic } \\
\text { index (LS\% } \pm \text { SEM) } \\
\text { of embryos (range) }\end{array}$ \\
\hline Two to 16 cell & 17 & $2(11.8)^{\mathrm{a}}$ & $2.2 \pm 1.1^{\mathrm{a}}(0-25)$ \\
Poor morula & 15 & $5(33.3)^{\mathrm{ab}}$ & $1.3 \pm 1.2^{\mathrm{a}}(0-6.8)$ \\
Good morula & 9 & $6(66.7)^{\mathrm{b}}$ & $2.9 \pm 1.6^{\mathrm{a}}(0-7.4)$ \\
\hline
\end{tabular}

${ }^{\mathrm{a}, \mathrm{b}}$ Values with different superscripts within the same column differ significantly.

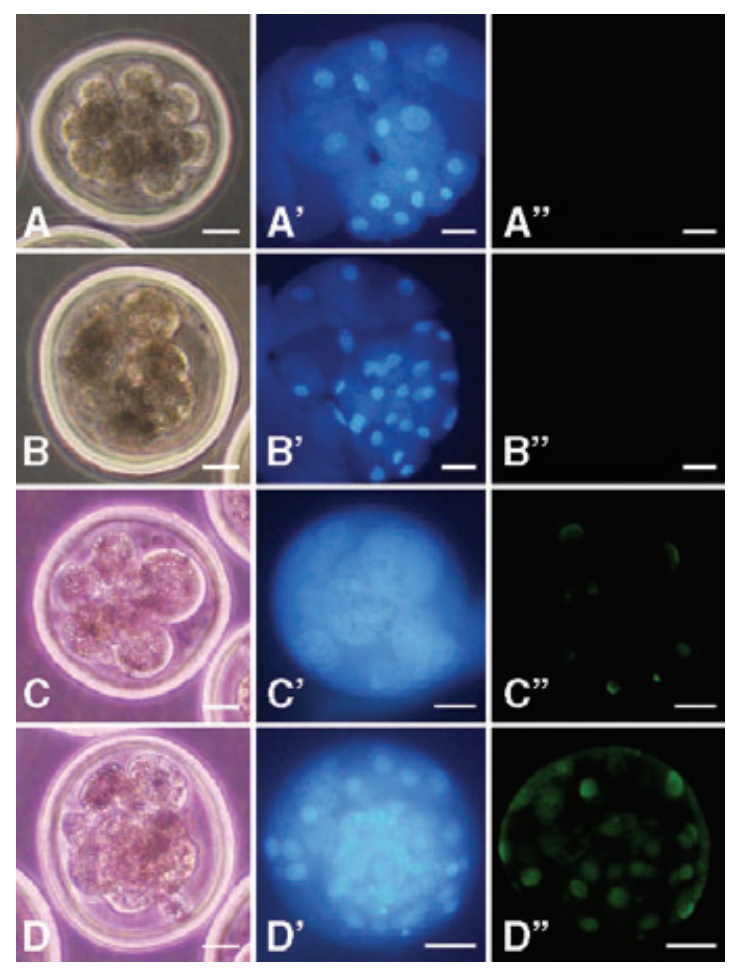

Fig. 1. Light microscopy (A-D), Hoechst staining $\left(\mathrm{A}^{\prime}-\mathrm{D}^{\prime}\right)$ and terminal deoxynucleotidyl transferase-mediated dUTP nick-end labelling (TUNEL) $\left(\mathrm{A}^{\prime \prime}-\mathrm{D}^{\prime \prime}\right)$ images of embryos with poor morphological quality recovered from superstimulated cows at day 7 post-insemination. TUNEL staining is hardly seen in the retarded embryo (A- $\left.\mathrm{A}^{\prime \prime}\right)$ and fragmented morula $\left(B-B^{\prime \prime}\right)$ but it can be seen in the positive controls $\left(\mathrm{C}-\mathrm{C}^{\prime \prime}\right.$ and $\left.\mathrm{D}-\mathrm{D}^{\prime \prime}\right)$. Scale bars represent $25 \mu \mathrm{m}$

range of $\mathrm{AI}$ in poor-quality morulae $(0-6.8 \%)$ was similar to that of good-quality morulae $(0-7.4 \%)$. As a consequence, the mean AI of morphologically poorquality embryos did not differ from that of good-quality embryos. The validity of the TUNEL experiments was confirmed by the positive staining in the control (Fig. $1 \mathrm{C}-\mathrm{C}^{\prime \prime}$ and $\mathrm{D}-\mathrm{D}^{\prime \prime}$ ) in which DNA had been degraded by DNase I.

\section{Discussion}

In the present study, more than half of the embryos that were considered as morphologically normal had at least one apoptotic cell; this was in agreement with the findings of other authors who described apoptosis as a naturally occurring process during mammalian preimplantation development (Hardy 1997, 1999; Gjorret et al. 2003; Mateusen et al. 2005). Many researchers reported that retarded and/or fragmented mammalian embryos underwent apoptosis as a preferential mode of cell death (Jurisicova et al. 1996; Yang and Rajamahendran 2002; Jurisicova and Acton 2004; Mateusen et al. 2005). However, in our present study, substantial proportion of the retarded (15/17) or fragmented (10/15) embryos collected from the MOET programme did not show any apoptosis and the mean AIs in the morphologically poor-quality embryos were as low as that in the good-quality embryos. Antczak and Van Blerkom (1999) showed that the apoptotic incidence was very 
low in human arrested or fragmented embryos, and the authors suggested the existence of fragmentation without apoptosis. Our results are consistent with this report. However, both reports do not deny the involvement of apoptosis in certain types of fragmentation. Embryos that are judged to be of a poor quality in the widely used morphology-oriented evaluation system are not necessarily lethal (Lindner and Wright 1983). It is possible that some of these embryos are developmentally normal and they do not need to activate apoptosis as a self-elimination system of defective cells (Hardy et al. 2003) or whole embryos (Jurisicova et al. 1998) proposed by some researchers.

The criteria for apoptosis used in this study were TUNEL staining with apoptotic morphology (Gjorret et al. 2003). Some researchers suggest that caspase staining is needed to better define an apoptotic stage in cells, decreasing the number of false positives and negatives (Walker and Quirke 2001; Mullen and Critser 2004). However, Martinez et al. (2002) found that caspase activity was seen not only in embryonic apoptotic fragments but also in fragments observed in goodmorphology human embryos which apparently had not lost a blastomere or fragments detached from healthy blastomeres that had been isolated by embryo biopsy and subsequently underwent mitotic division in culture. From these results, the authors suggested that caspases in pre-implantation embryos are involved in developmental processes unrelated to apoptotic cell death. Furthermore, this study also supports our hypothesis that some kinds of fragmentation occurs independently of apoptosis.

As shown in Fig. 1, the morphologically poor-quality morulae in the present study often showed fragmentation seemingly by asymmetric cell division rather than by the apoptotic process (Fig. 1B-B'). Our results indicate the possibility that embryonic fragmentation by asymmetric cell division is unrelated to apoptosis. Defects such as abnormal organization of the cytoskeleton (Wang et al. 1999), abnormal ploidy (King et al. 1987) and blastomere-specific depletion of regulatory proteins (Antczak and Van Blerkom 1999) could cause apoptosis-independent morphological poorness of embryos.

\section{Acknowledgements}

SI acknowledges the support of Research Fellowships of the Japan Society for the Promotion of Science (JSPS) for Young Scientists. This work was supported by Spanish Ministry of Education and Science, project AGL2005-04479.

\section{References}

Alikani M, Cohen J, Tomkin G, Garrisi GJ, Mack C, Scott RT, 1999: Human embryo fragmentation in vitro and its implications for pregnancy and implantation. Fertil Steril 71, 836-842.

Antczak M, Van Blerkom J, 1999: Temporal and spatial aspects of fragmentation in early human embryos: possible effects on developmental competence and association with the differential elimination of regulatory proteins from polarized domains. Hum Reprod 14, 429-447.
Armstrong DT, 1993: Recent advances in superovulation of cattle. Theriogenology 39, 7-24.

Gjorret JO, Knijn HM, Dieleman SJ, Avery B, Larsson LI, Maddox-Hyttel P, 2003: Chronology of apoptosis in bovine embryos produced in vivo and in vitro. Biol Reprod 69, 1193-1200.

Hardy K, 1997: Cell death in the mammalian blastocyst. Mol Hum Reprod 3, 919-925.

Hardy K, 1999: Apoptosis in the human embryo. Rev Reprod 4, 125-134.

Hardy K, Stark J, Winston RM, 2003: Maintenance of the inner cell mass in human blastocysts from fragmented embryos. Biol Reprod 68, 1165-1169.

Jurisicova A, Acton BM, 2004: Deadly decisions: the role of genes regulating programmed cell death in human preimplantation embryo development. Reproduction 128, 281291.

Jurisicova A, Varmuza S, Casper RF, 1996: Programmed cell death and human embryo fragmentation. Mol Hum Reprod 2, 93-98.

Jurisicova A, Latham KE, Casper RF, Casper RF, Varmuza SL, 1998: Expression and regulation of genes associated with cell death during murine preimplantation embryo development. Mol Reprod Dev 51, 243-253.

King WA, Guay P, Picard L, 1987: A cytogenetical study of 7day-old bovine embryos of poor morphological quality. Genome 29, 160-164.

Lindner GM, Wright RWJ, 1983: Bovine embryo morphology and evaluation. Theriogenology 20, 407-416.

Martinez F, Rienzi L, Iacobelli M, Ubaldi F, Mendoza C, Greco E, Tesarik J, 2002: Caspase activity in preimplantation human embryos is not associated with apoptosis. Hum Reprod 17, 1584-1590.

Mateusen B, Van Soom A, Maes DG, Donnay I, Duchateau L, Lequarre AS, 2005: Porcine embryo development and fragmentation and their relation to apoptotic markers: a cinematographic and confocal laser scanning microscopic study. Reproduction 129, 443-452.

Mullen SF, Critser JK, 2004: Using TUNEL in combination with an active caspase-3 immunoassay to identify cells undergoing apoptosis in preimplantation mammalian embryos. Methods Mol Biol 254, 393-406.

Robertson I, Nelson RE, 1998: Certification and identification of the embryo. In: Stringfellow DA, Seidel SM (eds), Manual of the International Embryo Transfer Society. International Embryo Transfer Society, Savoy, IL, pp. 103116.

Ryan TA, 1960: Significance tests for multiple comparison of proportions, variances, and other statistics. Psychol Bull 57, 318-328.

Walker JA, Quirke P, 2001: Viewing apoptosis through a 'TUNEL'. J Pathol 195, 275-276.

Wang WH, Abeydeera LR, Han YM, Prather RS, Day BN, 1999: Morphologic evaluation and actin filament distribution in porcine embryos produced in vitro and in vivo. Biol Reprod 60, 1020-1028.

Yang MY, Rajamahendran R, 2002: Expression of Bcl-2 and Bax proteins in relation to quality of bovine oocytes and embryos produced in vitro. Anim Reprod Sci 70, 159-169.

\section{Submitted: 01.12.2005}

Author's address (for correspondence): Shuntaro Ikeda, Livestock Farm of Graduate School of Agriculture, Kyoto University, 144 Komono, Tomita, Kyo-Tamba-cho, Funai-gun, Kyoto Prefecture 6220203, Japan. E-mail: shunta@kais.kyoto-u.ac.jp 